\title{
Substantiation of the Need to Create an Eccentric Cycloidal Gearing Transmission of Geokhod
}

\author{
Georgiy Dubov ${ }^{1, *}$, Dmitriy Trukhmanov ${ }^{1}$, Aleksey Chegoshev ${ }^{1}$, and Vitaliy Ashikhmin ${ }^{2}$ \\ ${ }^{1}$ T.F. Gorbachev Kuzbass State Technical University, Mechanical Engineering Technology \\ Department, 650000, Kemerovo, 28 Vesennya st., Russian Federation \\ ${ }^{2}$ T.F. Gorbachev Kuzbass State Technical University, Car Operation Department, 650000, Kemerovo, \\ 28 Vesennya st., Russian Federation
}

\begin{abstract}
The state of the issue of the underground space development rate in Russia is considered. An analysis of shortcomings of the existing tunneling equipment (tunneling shields and machines) is carried out. It is noted that a promising way of mine tunneling is screw drilling technology, the basic functional element of which is the geokhod. It is claimed that one of the key systems of the geokhod, which determines its efficiency, is transmission. It is noted that the hydraulic cylinder type transmissions implemented in practice at the present time in the form of the development prototype have both their advantages and disadvantages. This does not allow considering the hydraulic cylinder type transmission the optimal solution for its use when designing new-generation geokhod. An overview of various gearing types is made and conclusions about the prospects of using them in the geokhod transmission are drawn. It is claimed that the eccentric cycloidal gearing, according to a set of indicators, is the most suitable for its application in the geokhod transmission. Therefore, studies aimed at proving parameters of the eccentric cycloidal gearing geokhod transmission are relevant.
\end{abstract}

\section{Introduction}

The need for solid minerals in the world increases annually by $0.6-1.5 \%$. In the program for the development of the Russian coal industry, it is planned to increase coal production to 500 million tons per year by 2030 . The achievement of these volumes is possible only with the mining of new deposits in Siberia and the Far East. This will lead to the formation of a significant demand for mobile and high-performance tunneling equipment, since the underground mine tunneling is one of the most labor-consuming and capital-intensive processes in mining chain. The bulk of the workings is tunneled and is planned to be tunneled by conventional equipment - tunneling shields and machines. However, due to a number of design features, these tunneling aggregates have a number of significant disadvantages:

- low maneuverability;

\footnotetext{
*Corresponding author: nikokem@mail.ru
} 
- difficulty in creating sufficient traction and pressure forces (the conventional way of ensuring such forces by means of increasing in the mass of tunneling aggregates, which has long exceeded 100 tons, does not fully solve this problem);

- limited use in terms of the inclination angles when tunneling (in the case of inclined and vertical workings there is a need to apply special sets of tunneling equipment);

- relatively low tunneling rates;

- inability to fully ensure safety in the bottom-hole zone;

- impossibility of adaptation for the building-block approach [1].

The indicated drawbacks make the use of conventional tunneling equipment inefficient for achieving the working volumes dictated by the current needs of the industry.

One of the responsible and stressed parts of mining machine is transmission, which determines, among others, its mass and dimensions. The main components of transmission are gear wheels, on the operability of which the reliability and durability of the machine as a whole largely depends on.

The actual loading regime of mining machines is a random non-stationary process with frequent changes in the periods of action of the loads and their absence. The complexity of operating conditions, the heterogeneity of the properties of the coal mass also leaves its mark on the process of loading the mining machine, causing its nonsteady state. The contact with solid inclusions leads to the appearance of peak loads in the drive. When the executive body is completely stopped, the load in the drive exceeds the load of the starting and maximum torque developed by the engine. Often in these cases, the startup is carried out by switching in several series, since the moment of the resistance forces, which is caused by the executive body buckling, is significant. Such short-term high-level loads lead to the occurrence of irreversible phenomena in the elements of transmissions, further leading to a decrease in its longevity. These operating conditions determine the choice of gearing geometry, the material of gear pairs and the processes of their manufacture.

The purpose of this study was to study various gearing types with the prospect of their further application in the geokhod transmission.

\section{Results and discussions}

An alternative method of sinking and tunneling is screw drilling technology - the process of mechanized underground tunneling involving contour strata (geo-environment), through the development of a system of channels outside the contour [1-3]. In addition to the underground tunneling, another purpose of screw drilling technology can be the provision of emergency rescue operations in the aftermath of anthropogenic disasters and in emergency situations in mining enterprises [3]. A tunneling unit that implements screw drilling technology is the geokhod [1-4]. Currently, work is underway to create a new generation geokhod and its systems [5-11].

As in any mining machine, a mechanism - a transmission - that converses the energy supplied from the power plant and transfers the required force to the external propulsion is needed for the movement of the geokhod. It is the geokhod transmission that determines the limiting values of the developed engine torque and the speed of movement in geoenvironment.

Previously, in the development prototype of the geokhod, a transmission with chordwise hydraulic cylinders acting in antiphase [12-13] was applied. To achieve the uniform motion, the hydraulic cylinders work alternately - when the rods of the hydraulic cylinders of one group are extended, the rods of the other group make a reverse move [12-13]. One of the layout schemes that implements the described principle of operation is shown in Fig. 1 (in 
the development prototype, a similar scheme was implemented, but hydraulic cylinders were grouped in two planes).

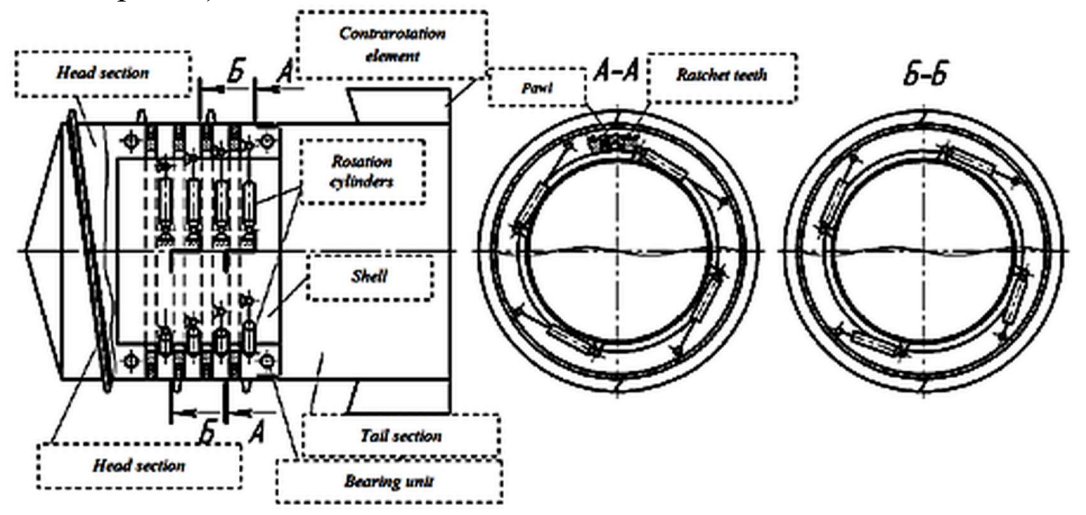

Fig.1. Layout schemes with various phases of hydraulic cylinder extension, grouped in four planes [12].

However, despite the advantages of this constructive solution for the geokhod transmission (the control convenience, the provision of the necessary free space within the geokhod, the ability to develop high torques, etc.), there is also a number of significant shortcomings in it, the main of which are [12-16]:

- high requirements to the production accuracy and the complexity of installation and repair in the cramped conditions of the bottom-hole zone in the underground tunneling and sinking; - difficulty of achieving a continuous geokhod movement;

- complexity of synchronization of hydraulic cylinders due to the peculiarities of hydraulic systems;

- due to the continuous rotation, only a part of the hydraulic cylinders participates in the formation of torque;

- complexity of organization of reverse movement of the geokhod;

- twisting of high pressure hoses (HPH) during the rotation of the head section.

The presence of these shortcomings does not make it possible to consider the hydraulic cylinder transmission as the most suitable solution for the use as a new-generation geokhod transmission and creates the prerequisites for further research in this field and the consideration of another transmission types.

One of the ways to solve the indicated problems can be the creation of a gear transmission for the geokhod. In particular, when using a gear transmission, installation and repair are simplified; there are no problems associated with the complexity of providing the continuity of the geokhod movement and its reverse, as well as the problems specific to hydraulic equipment. However, not all gearing types can be used in high-loaded transmissions, furthermore, in the aggressive operating environment of the underground tunneling.

The most common is an involute gear. However, despite all advantages, this type of gearing also has shortcomings, primarily associated with a relatively low load capacity, determined by the size of the teeth, and also with the limitation in the magnitude of the gear ratio in one tooth spacing - in practice it rarely exceeds 7 .

One of the main directions in solving the problem of increasing the strength and the service life of involute gears in the transmissions of mining machines should be considered bringing the wheels to 7-8 accuracy degree. This is achieved by grinding and finishing, but significantly complicates their production and increases the cost of manufacturing. 
Cycloidal lantern-wheel gearing [17] and Novikov-Wilbhaber gearing [17-19] are the most known among the gearing types, which have a number of advantages over an involute gearing. However, these gearings have not found wide application, because having a higher load capacity and higher efficiency they are inferior to an involute gearing, in particular, in terms of manufacturability. Because, they are much more sensitive to the interaxial distance shift, and they require a higher manufacturing precision.

Recently a new gear transmission - eccentric cycloidal gearing - mechanisms have been spreading. In particular, the axial traction gearbox of railway locomotive MPT 6 , the axle drive gear of BelAZ-755, the traction gearbox of underground electric locomotive K-25, as well as the open reducers of cooling towers, booster compressor on oil fields, gear multiphase pump, submersible pump for oil production, mud pump, wind-energy unit reducer, steam turbines, steering column DRK-8500L, torque amplifier UKM1700, helical reducer, gearboxes of open-pit mine excavators, antenna rotation reducer, etc. were produced and put into operation on the basis of this gearing.

The transverse section of the working face of the tooth of the driving gear of the eccentric cycloidal gearing is a circle that is eccentric relative to the gear rotation axis, and the teeth of the driven gear have a profile in the form of a cycloidal curve (Figure 2) [17]. Due to this design, the eccentric cycloidal gearing teeth work to collapse [17-19], and not to bend, as in an involute gearing, that allows providing a wide range of gear ratios, with a minimum gear mass per unit of transmitted torque. The contact pattern increased due to the rounded shape of the tooth allows reducing the specific pressure and thereby increasing the load capacity of the teeth. And a constant contact of the gears allows getting rid of noise and vibration [17$19]$.

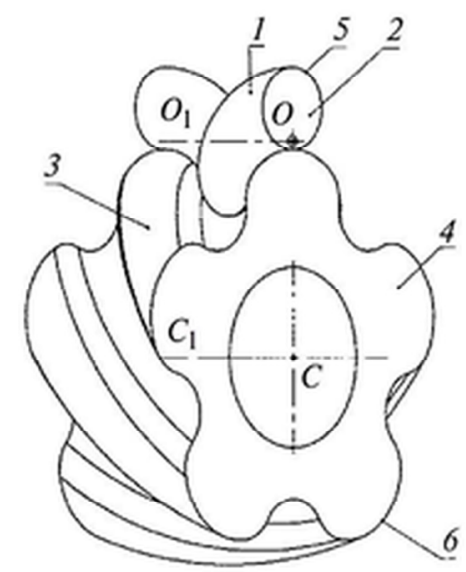

Fig. 2. Ideal gearing teeth surfaces 1 - helical gear surface; 2, 3- helical gear teeth surface; 4, 5 eccentric circle; 6 -cicloidal curve in transverse section of gear [19].

According to the results of computer simulations conducted - eccentric cycloidal gearing allows much greater deviations from the calculated interaxial distance than an involute gearing, and the location of the contact pattern on the tooth surface allows the vertices and cavities of the teeth to be of arbitrary shape. All this allows significant reducing the area of surfaces that require precise processing.

Within the framework of the advance project of the Perspective Research Foundation at Krylov State Scientific Center (St. Petersburg), comparative tests with JSC ZAREM involute gearing test reducer 5C2-125-12,5 were carried out. During the tests, it was found that the efficiency in eccentric cycloidal gearbox is $2 \%$ higher, and the ultimate breaking point is more by $25 \%$. Despite the absence of actual evidence for some of the declared characteristics 
of eccentric cycloidal gearing, its production is more technological, with respect to other types of gearing.

An important fact is that the manufacture of eccentric cycloidal gearings can be performed on less expensive equipment, in contrast to the manufacture of other gearing types.

\section{Conclusion}

The analysis of the gearing allows making a preliminary conclusion that the eccentric cycloidal gearing is one of the most promising for its application in the geokhod transmission. However, the lack of technically and scientifically proven solutions for the geokhod transmission of this gearing type, as well as the methods for determining its parameters, hampers ongoing work on the design of new-generation geokhod. Therefore, studies aimed at substantiation of parameters of eccentric cycloidal gearing transmission of the geokhod are relevant.

\section{References}

1. A.B. Efremenkov, Proceedings of the 6th international forum on strategic technology, 1, $348(2011)$

2. V.V. Aksenov, A.A. Khoreshok, V.Y. Beglyakov, Appl. Mech. Mater., 379, 20 (2013)

3. V.V. Aksenov, T.B. Rogova, S.V. Shaklein, Appl. Mech. Mater., 770, 718 (2015)

4. A.B. Efremenkov, V.Y. Timofeev, 7th international forum on strategic technology, 1, 6357729 (2012)

5. V. Yu. Sadovets, V.Yu. Beglyakov, A.B. Efremenkov, Appl. Mech. Mater., 770, 384 (2015)

6. M.Yu. Blaschuk, A.A. Dronov, D.A. Miheev, Appl. Mech. Mater., 770, 391 (2015)

7. A.V. Walter, V.V. Aksenov, Appl. Mech. Mater., 770, 439 (2015)

8. V. Aksenov, V. Sadovets, E. Rezanova, D. Pashkov, 1st Scientific Practical Conference International Innovative Mining Symposium (In Memory of Prof. Vladimir Pronoza), 15, 03015 (2017)

9. V. Aksenov, I. Chicherin, I. Kostinez, A. Kazantsev, A. Efremenkov, 1st Scientific Practical Conference International Innovative Mining Symposium (In Memory of Prof. Vladimir Pronoza), 15, 030000 (2017)

10. V.V. Aksenov, V.Y. Beglyakov, A.A. Kazantsev, I.V. Doroshenko, International Scientific and Practical Conference on Urgent Problems of Modern Mechanical Engineering, 15, 12031 (2016)

11. V.V. Aksenov, V.Y. Beglyakov, A.A. Kazantsev, A.S. Saprykin, International Scientific and Practical Conference on Urgent Problems of Modern Mechanical Engineering, 1, 12032 (2016)

12. A.B. Efremenkov, V.V. Aksenov, M.Yu. Blashchuk, 7th international forum on strategic technology, 1, 6357716 (2012)

13. V.V. Aksenov, M.Y. Blaschuk, M.V. Dubrovskii, Appl. Mech. Mater., 379, 11 (2013)

14. V.Yu. Timofeev, V.V. Aksenov, J.I. Galjamova, Appl. Mech. Mater., 682, 246 (2014)

15. V. Yu. Timofeev, V. Yu. Beglyakov, M.V. Dokhnenko, Appl. Mech. Mater., 682, 246 (2014) 
16. M. Blaschuk, A. Dronov, A. Koperchuk, R. Chernukhin, V. Litvinenko, 1st Scientific Practical Conference International Innovative Mining Symposium (In Memory of Prof. Vladimir Pronoza), 15, 3003 (2017)

17. S.M. Kazakyavichyus, V.V. Stanovskoy, T.A. Remneva, Russian Engineering Research, 5, 439 (2009)

18. S.M. Kazakyavichyus, V.V. Stanovskoy, T.A. Remneva, Antriebstechnik, 11, 78 (2009)

19. S.M. Kazakyavichyus, V.V. Stanovskoy, T.A. Remneva, Russian Engineering Research, 3, 197 (2011) 